\title{
Políticas públicas educacionais e suas multirregulações
}

\section{Igor Rodrigues Gandra}

Universidade Federal do Estado do Rio de Janeiro (Unirio), Rio de Janeiro/RJ - Brasil Isabelle Premoli Parada

Universidade Federal do Estado do Rio de Janeiro (Unirio), Rio de Janeiro/RJ - Brasil Millena Lopes Rocha

Universidade Federal do Estado do Rio de Janeiro (Unirio), Rio de Janeiro/RJ - Brasil

BARROSO, João (Org.). A regulamentação das políticas públicas de educação: espaços, dinâmicas e actores. Lisboa: Educa, 2006.

A obra organizada por João Barroso foi publicada há 11 anos, mas se faz atual, por trazer elementos essenciais para a reflexão sobre a regulação das políticas públicas no contexto educacional. Torna-se, assim, leitura fundamental para os estudos em política da educação, especialmente para aqueles que pretendem compreender as dinâmicas de implementação que envolvem atores e dinâmicas específicos aos seus espaços e contextos de atuação. O livro é composto por sete capítulos, escritos pelos professores pesquisadores responsáveis pelo projeto Reguleducnetwork: Changes in regulation modes and social production in inequalities in educational systems: a European comparison. O principal objetivo do projeto foi comparar o desenvolvimento da regulação das políticas públicas na educação secundária dos países em estudo (Portugal, França, Bélgica, Hungria e Reino Unido) e analisar de que modo as transformações nas políticas educacionais em curso afetam a organização da escola, incluindo o modo como os atores locais intervêm no processo de reprodução e produção das desigualdades e da segregação escolar.

A introdução do livro busca explicitar as abordagens do autor em sua análise sobre a regulação das políticas públicas e os métodos utilizados para compor cada capítulo. Além disso, apresenta ao leitor as definições de política pública e regulação. O primeiro conceito envolve a compreensão do estudo e das ideias que orientam a tomada de decisão, as consequências de suas ações e a relação entre a autoridade e os atores. Já a regulação é dividida em caráter institucional (governo e sua hierarquia) e caráter autônomo (atribuído aos atores). Concomitantemente, é apresentado um levantamento de teses e 
dissertações sobre o tema, com seus referenciais teóricos e desenhos metodológicos, para fundamentar o trabalho e pesquisa desses autores.

O primeiro capítulo do livro, de autoria de Barroso, propõe um estudo acerca da atual composição do poder do Estado e de como ela afeta a função de diferentes atores que participam das mais diversas formas do processo educativo. Essa discussão abre espaço para uma abordagem em torno de demandas de políticas públicas da educação em Portugal e de como elas são reguladas. São apresentadas três formas de regulação dessas políticas: transnacional, nacional, e microrregulação local. Utilizando o termo "metarregulação", Barroso propõe romper com a ideia de verticalização do poder do Estado na implementação das políticas educacionais, passando ao papel de regulador das regulações. O autor também discute os conflitos de interesses entre as regulações estatais e corporativas, sobre a relação entre as normas do sistema educacional e a autonomia profissional. Ressalta-se, ainda, que, quando se fala de regulação no sentido das políticas públicas da educação, a multirregulação é o termo mais adequado a ser usado, pois todas as formas de regulação anteriormente abordadas estão acontecendo ao mesmo tempo.

No segundo capítulo, escrito por Natércio Afonso, foi feita uma análise das práticas de regulação levadas a cabo pelos atores da Direção Regional da Educação de Lisboa (Drell), enquanto instituição de nível meso. A etapa da pesquisa narrada neste capítulo explicita quem são e o que fazem os atores e administradores que assegurarão a orientação, coordenação e apoio às microrregulações, que envolvem o trabalho dos dirigentes e dos técnicos. A partir dos discursos desses atores, Afonso aborda questões como a desconcentração da administração da educação e a promoção da autonomia nas escolas. O autor argumenta que a regulação burocrática (ou meso, ou nacional) e a regulação corporativa de tipo profissional são modelos antagônicos, contudo complementares, pois coexistem entre tensões e de maneiras diversificadas, em diversos domínios públicos e contextos históricos.

No terceiro capítulo, João Pinhal discorre sobre a presente intervenção dos municípios na educação portuguesa, que aconteceu pós-revolução de 1974. O município é considerado a autarquia de maior dimensão e com maior capacidade para intervir sobre os currículos das escolas portuguesas. Entretanto, essa instância não poderia interferir diretamente nas escolas 
através de atividades educativas. Foram apresentadas algumas medidas tomadas para que a autarquia pudesse ajudar as escolas, por exemplo, fornecendo subsídios, em dinheiro, materiais ou logística, para que elas possam implementar atividades extracurriculares. Mediante as atividades propiciadas pela gestão municipal (através da carta educativa e do conselho municipal de educação), o autor conclui que essa gestão favorece a criação de uma complexidade de multirregulações locais, introduzindo fatores de ambiguidade e de adaptação na regulação central.

No quarto capítulo, João Barroso e Sofia Viseu dão continuidade às análises sobre a criação de novos espaços de regulação da oferta educativa, ao nível das relações que se estabelecem entre escolas pertencentes a um mesmo território. A análise da regulação interescolar reflete a maneira como é ou não garantida a igualdade de oportunidades. Na busca por novos espaços e meios de reorganizar as políticas públicas da educação, são criadas duas medidas extremamente antagônicas. Os autores mostraram que uma das medidas é a adoção de um sistema neoliberal da gestão, centrada na escola, com o intuito de criar um quase mercado de educação. Esse sistema busca estar livre, totalmente, das mãos do Estado. Já a segunda medida quer ajustar o modelo vigente, com a intenção de corrigir aquilo que seus promotores acreditam estar errado. Assim, o estudo feito pelo projeto Reguleducnetwork conclui que, tanto as políticas educacionais baseadas numa lógica de mercado (livre escolha da escola), quanto as políticas de matrícula direcionada (carta educacional) favorecem a existência de segregação social e escolar.

No capítulo cinco, Barroso e colegas apresentam uma investigação comparativa feita entre duas escolas (Rosa e Azul), com o objetivo de perceber o que torna uma mais atrativa do que a outra. Os autores ressaltam que ambas se distinguem nas suas características e estratégias de gestão. O capítulo se inicia com uma breve explicação dos conceitos de regulação e poder de atração. Sucintamente, a atratividade passou a ser entendida como a capacidade que a escola demonstra ter de suscitar a vontade dos alunos em querer frequentá-la, enquanto regulação é entendida como os processos formais e informais, que garantem a coordenação da ação coletiva na escola, através da produção e manutenção de regras que asseguram o seu funcionamento. Para a continuidade desse processo, é necessário incluir a "regulação de controle", a "regulação autônoma" e a "regulação conjunta". 
Posteriormente, foi analisado o poder de atratividade de cada escola, ficando evidente que ambas atraem públicos bem diferentes, mas têm em comum o fato de serem lideranças fortes e marcantes. Os autores utilizam a expressão "lógicas de ação", para se referir ao modo de organizar e também coordenar a ação coletiva, fazendo, assim, com que ela tenha uma logística a ser seguida quando executada. As lógicas de ação buscam colocar em prática ações dos atores de determinada regulação, de maneira que eles possam dar sentido às suas práticas e escolhas. Esse termo é constantemente associado à ideia de racionalidade e de legitimação, pois é considerado uma justificação das decisões.

O capítulo seis, escrito por Agnès van Zanten, propõe-se a realizar uma análise dos processos competitivos e tem como objeto de estudo as cidades do Projeto Reguleducnetwork. Elas foram escolhidas com base em alguns fatores comuns: a presença de uma população heterogênea e a grande diversificação de oferta educacional em instituições públicas e privadas. São abordados os conceitos de interdependência competitiva, lógica de ação e modelo de análise. A autora realiza uma análise sobre a forma através da qual a autonomia de diferentes domínios escolares acontece nos territórios analisados. Os domínios são divididos entre os que possuem características internas e externas. Os de características externas são: recrutamento de alunos, oferta de opções curriculares e promoção da escola. Já os que têm uma orientação mais interna são: distribuição dos alunos pelas turmas, apoio a crianças com necessidades educativas especiais e resolução de problemas disciplinares.

No sétimo capítulo, Christian Maroy faz uma retomada de todos os tópicos importantes que tinham sido abordados nos capítulos anteriores, apresentando as conclusões do projeto. Com isso, ele reforça ideias e conceitos, como regulação e seus tipos, atores sociais envolvidos, lógicas de ação e sistema de quase mercado. Nesse capítulo, é dado um enfoque às convergências e divergências, que determinados locais podem ter em relação à implementação das políticas públicas. Demonstra-se, assim, que determinados países possuem algumas similaridades na maneira de efetuar determinadas regulações (convergência), e outros possuem muita diferenciação na sua aplicação (divergência). Desse modo, é possível fazer uma análise comparativa entre os países, que auxilia no entendimento da tipificação de educação de cada um dos locais estudados. 
O autor apresenta a relação de competitividade entre as escolas, porém, também aborda as relações de cooperatividade, citando os clusters. As escolas em competição se ajudam, pois coabitam o mesmo local e possuem algumas similaridades. Com isso, podem obter vantagens, se caminharem juntas, formando, assim, um tipo de rede de interesses. Essa seria apenas mais uma das formas de as escolas aumentarem a captação de alunos e fazer com que 0 seu status cresça no local em que ficam localizadas. Maroy traz algumas conclusões do estudo, como, por exemplo, que as lógicas de ação podem coexistir e ter efeitos adversos; e que a regulação de políticas públicas educacionais vai além das estratégias administrativas e de gestão, compreendendo ações políticas, podendo ser considerada uma estratégia contra a desigualdade.

A leitura da obra nos remete à reflexão sobre as políticas educacionais, em um contexto de multirregulações, distanciando-se de uma compreensão unilateral (de cima para baixo) na implementação das políticas públicas. Propõe a análise das diferentes formas através das quais os atores as colocam em prática, considerando que as escolas estão inseridas em contextos sociais diversificados e muitas vezes complicados. Os problemas e tendências que foram encontrados nas lógicas de ação desses atores possuem relação direta com o contexto: a desigualdade, a segregação e o mercado. Nesse sentido, as ações tomadas a partir das definições das políticas educacionais devem ser compreendidas não apenas no âmbito escolar, mas sim desde a sua formulação enquanto política de Estado, passando por todos os atores envolvidos nos processos de regulação. Assim, a leitura nos ajuda a ampliar as possibilidades de entendimento dos sistemas sociais, da complexidade diante das arenas políticas nacionais e locais, das estratégias, do impacto das tendências dos modelos de regulação nas políticas e nas práticas educativas. 